\title{
Monoclonal Antibodies Specific for Fixative-Modified Aspartate: Immunocytochemical Localization in the Rat CNS
}

\author{
James E. Madl, Alvin J. Beitz, Rodney L. Johnson, ${ }^{1}$ and Alice A. Larson \\ Department of Veterinary Biology, University of Minnesota, St. Paul, Minnesota 55108, and 'Department of Medicinal \\ Chemistry and Pharmacognosy, University of Minnesota, Minneapolis, Minnesota 55455
}

Aspartate is a putative excitatory amino acid neurotransmitter that is widely distributed in the CNS. To study its distribution, monoclonal antibodies were produced against $\beta$-L-aspartyl-L-aspartate ( $\beta$-Asp-Asp) conjugated to keyhole limpet hemocyanin (KLH) using glutaraldehyde-borohydride. Three monoclonal antibodies, Asp1-3, were obtained with high degrees of selectivity for aldehyde-fixed aspartate. The immunocytochemical staining pattern of rat CNS was found to be similar for all 3 antibodies but differed in some regions from staining patterns produced by Glu1, a monoclonal antibody with high selectivity for a form of amidelinked glutamate. Tissue staining produced by Asp1-3 could be inhibited using aspartate conjugated to carrier proteins. Staining by Asp1 and Asp2 was also inhibited by free small molecules containing aspartate. Specificity of the 3 antibodies was evaluated by enzyme-linked immunoassay (ELISA) as follows: (1) reactivity of antibodies for conjugates of small molecules coated on ELISA plates; (2) ability of free small molecules to inhibit reactivity of antibodies for $\beta$-AspAsp/KLH coated on ELISA plates; and (3) ability of conjugates to inhibit reactivity of antibodies for $\beta$-Asp-Asp/KLH coated on ELISA plates. In all 3 types of assays, Asp1 and Asp2 displayed strong reactivity for small molecules and conjugates containing aspartate and little reactivity for small molecules and conjugates containing glutamate or GABA. Asp3 was highly reactive with conjugates containing aspartate using both direct and inhibition ELISA assays. For all 3 antibodies the precise staining pattern varied with the fixative used. Following glutaraldehyde fixation, dense immunocytochemical staining was observed in cerebral cortical neurons, some cerebellar granule cells, hippocampal pyramidal cells, and neurons of the inferior olivary nucleus. In addition, some putative GABAergic neurons, e.g., cerebellar basket and stellate cells, appeared to be stained. In general, acrolein fixation resulted in a more selective staining pattern in the CNS. For example, putative GABAergic neurons were no longer immunoreactive nor were hippocampal pyramidal cells.

Received Nov. 14, 1985; revised Jan. 23, 1987; accepted Mar. 10, 1987.

This work was supported by United States Public Health Service Grants DE 06682, NS 19208, NS 17407, and NS 07367 and Grant BNS 83-11214 from the National Science Foundation. We wish to thank Gene Palmer and Mary Mullet for their able technical assistance.

Correspondence should be addressed to James E. Madl, Department of Veterinary Biology, 295 AnSci/VetMed Bldg., University of Minnesota, St. Paul, MN 55108.

Copyright (C) 1987 Society for Neuroscience $0270-6474 / 87 / 092639-12 \$ 02.00 / 0$
Aspartate and glutamate are found in millimolar concentrations throughout the CNS of mammals. A wealth of electrophysiologic and biochemical evidence supports the concept that these amino acids play major roles in excitatory neurotransmission in many regions of the CNS (for reviews, see Watkins and Evans, 1981; Fonnum, 1984). A recent microdissection study indicates variations in aspartate and glutamate concentrations among brain nuclei (Palkovits et al., 1986).

Aspartate and glutamate are transported into axonal terminals by high-affinity, sodium-dependent uptake systems (Balcar and Johnson, 1972; Divac et al., 1977) and are released in a calciumdependent fashion upon depolarization of neuronal terminals (Sandoval and Cotman, 1978; Pearce and Dutton, 1981). Glutamate and aspartate also resemble each other pharmacologically in that responses to these amino acids are sensitive to some of the same antagonists (Watkins and Evans, 1981). Recent studies have also indicated the importance of excitatory amino acid release from neurons in the pathogenesis of ischemic necrosis in the CNS (Benveniste et al., 1984; Rothman, 1984; Simon et al., 1984).

Recently, aspartate has been localized in the CNS by immunocytochemical methods using polyclonal antisera (Ottersen and Storm-Mathisen, 1985; Campistron et al., 1986). We have reported the use of a monoclonal antibody for the immunocytochemical localization of glutamate-containing compounds (Madl et al., 1986). The present study describes the localization of aspartate-like immunoreactivity in the rat CNS using monoclonal antibodies that have low cross-reactivity with glutamate and other small molecules found in the CNS and briefly compares the distribution of aspartate-like immunoreactivity in select regions with that previously reported, as well as with that of glutamate-like immunoreactivity.

\section{Materials and Methods}

Small molecules. Small molecules including dipeptides were obtained from Sigma (St. Louis), with the exceptions of $\beta$-L-aspartyl-L-aspartic acid and $\gamma$-aminobutyryl- $\gamma$-aminobutyric acid, which were synthesized using the following procedures. All molecules were the L-isomer unless otherwise specified.

Beta-L-aspartyl-L-aspartic acid- $\mathrm{HCl}$ synthesis. Boc- $\alpha$-OBut-L-Asp $(1.0$ $\mathrm{gm}, 3.46 \mathrm{mmol})$ was coupled to $\mathrm{Asp}\left(\mathrm{OBu}^{t}\right)-\mathrm{OBu}^{t} \cdot \mathrm{HCl}(1.0 \mathrm{gm}, 3.55$ mmol) using the mixed anhydride method of Anderson et al. (1967). The crude product obtained after workup was recrystallized from a mixture of hexane and $\mathrm{Et}_{2} \mathrm{O}$ to give $1.4 \mathrm{gm} \mathrm{Boc}-\alpha-\mathrm{OBu}^{\mathrm{t}}-\beta-\mathrm{Asp}-\beta-\mathrm{OBu}^{\mathrm{t}}-$ Asp-OBut: melting point, $103-105^{\circ} \mathrm{C} ;[\alpha]_{\mathrm{D}}{ }^{24} 28.5^{\circ}\left(\mathrm{c} 1.0, \mathrm{CH}_{2} \mathrm{Cl}_{2}\right) . \mathrm{A}$ portion of the above protected dipeptide $(0.4 \mathrm{gm}, 0.77 \mathrm{mmol})$ was treated with $10 \mathrm{ml}$ of $4 \mathrm{~N} \mathrm{HCl}$ in dioxane for $1 \mathrm{hr}$. The $\mathrm{HCl}$ and dioxane were removed in vacuo, and the residue that remained was triturated with absolute ethanol before being collected. A yield of $50 \mathrm{mg}$ was obtained. Thin-layer chromatography (ninhydrin visualization): $R_{f}=$ 
0.26 [ $n$-butanol-HOAc- $\left.\mathrm{H}_{2} \mathrm{O}(7: 2: 1)\right] ; R_{f}=0.51$ [ $n$-butanol-HOAcEtOAc- $\left.\mathrm{H}_{2} \mathrm{O}(1: 1: 1: 1)\right]$. Nuclear magnetic resonance spectrum $\left(\mathrm{D}_{2} \mathrm{O}\right) \delta$ 2.84-3.04 (m,4H, Asp $\left.\beta-\mathrm{CH}_{2}\right), 4.08$ (dd, $J=4.8$ and $7.2 \mathrm{~Hz}, 1 \mathrm{H}, \beta$-Asp $\alpha-\mathrm{CH}), 4.7(\mathrm{t}, J=6.4 \mathrm{~Hz}, 1 \mathrm{~Hz}, \mathrm{Asp} \alpha-\mathrm{CH})$.

Gamma-aminobutyryl- $\gamma$-aminobutyric acid synthesis: Boc-GABA (1 $\mathrm{gm}, 4.9 \mathrm{mmol})$, and $\mathrm{GABA}-\mathrm{OMe} \cdot \mathrm{HCL}(0.75 \mathrm{gm}, 4.9 \mathrm{mmol})$ were coupled using the mixed anhydride method (Anderson et al., 1967). Upon workup in the usual manner, $1.05 \mathrm{gm}$ Boc-GABA-GABA-OMe was obtained: melting point, $69-71^{\circ} \mathrm{C}$. The above ester was hydrolized using a 1:1 mixture of $\mathrm{MeOH}$ and $2 \mathrm{~N} \mathrm{NaOH}$ to give Boc-GABA-GABA$\mathrm{OH}$ as an oil. This material was characterized as its dicyclohexylammonium salt: melting point $127-128^{\circ} \mathrm{C}$. The tert-butoxycarbonyl protecting group of Boc-GABA-GABA was removed using a 1:1 mixture of trifluoroacetic acid and $\mathrm{CH}_{2} \mathrm{Cl}_{2}$ at room temperature. The trifluoroacetic acid and $\mathrm{CH}_{2} \mathrm{Cl}_{2}$ were removed in vacuo. The residue obtained was placed on an AG50W-X8 cation exchange column (200-400 mesh). The product was eluted from the column using $2 \mathrm{~N} \mathrm{NH}_{4} \mathrm{OH}$. The fractions containing the desired GABA-GABA were lyophilized and the residue obtained recrystalized from $95 \% \mathrm{EtOH}$ to give GABA-GABA: melting point $180-181^{\circ} \mathrm{C}(\mathrm{dec})$. Thin-layer chromatography: $R_{f}=0.25$ [ $n$-butanol-HOAc- $\mathrm{H}_{2} \mathrm{O}(7: 2: 1)$ ninhydrin visualization]; $R_{f}=0.03$ [ $n$ propanol- $\mathrm{NH}_{4} \mathrm{OH}(4: 1)$ dichlorophenol-indophenol visualization].

Coupling of small molecules to carrier proteins. Conjugates for immunization were made as described previously (Madl et al., 1986) using equimolar amounts of the various small molecules. This procedure involved reacting $0.053 \mathrm{mmol}$ of small molecules and $30 \mathrm{mg}$ of carrier protein with glutaraldehyde followed by reduction with borohydride using the method of Geffard et al. (1984), after which the conjugates were extensively dialyzed. Additional conjugates of amino acids to BSA (Sigma) were made with $4 \%$ acrolein (Polysciences, Warrington, PA ) in $0.1 \mathrm{M}$ PBS ( $\mathrm{pH} \mathrm{7.2)}$ ) or with $4 \%$ paraformaldehyde in PBS or $5 \%$ glutaraldehyde in PBS. Efficiency of conjugation of amino acids to BSA in PBS was measured by adding $10 \mu \mathrm{Ci}$ of tritiated aspartate $(6.21 \times$ $10^{-5} \mathrm{M}, 16.1 \mathrm{Ci} / \mathrm{mmol}$; Amersham, Arlington Heights, IL), glutamate $\left(2.78 \times 10^{-5} \mathrm{M}, 36 \mathrm{Ci} / \mathrm{mmol}\right.$, Amersham), glycine $\left(8.77 \times 10^{-5} \mathrm{M}, 11.4\right.$ $\mathrm{Ci} / \mathrm{mmol}$, Amersham), or taurine $\left(3.45 \times 10^{-5} \mathrm{M}, 29 \mathrm{Ci} / \mathrm{mmol}\right.$, Amersham) to the conjugation reactions. Beta-counting was performed on $100 \mu \mathrm{l}$ aliquots of the reaction mixture before and after dialysis for $2 \mathrm{~d}$ at $4^{\circ} \mathrm{C}$.

Immunization. Four-week-old, male Balb/c/umc mice (University of Minnesota colony) were immunized with $\beta$-Asp-Asp/KLH conjugates following the schedule previously described in Madl et al. (1986). Two subcutancous injections of the conjugate in adjuvant were administered 3 weeks apart, followed by a final intraperitoneal injection of the conjugate $72 \mathrm{hr}$ before sacrificing mice and removing their spleens.

Cell fusion and screening. Spleen cells obtained from 2 mice immunized with each conjugate were fused with myeloma cells $(\mathbf{P} 3 \times 63$ Ag8.653) using the method described by Oi and Herzenberg (1980) with the following modification. Red blood cells present in spleen cells obtained from immunized mice were lysed before counting by suspension in $5 \mathrm{ml} 0.17 \mathrm{M}$ ammonium chloride at $4^{\circ} \mathrm{C}$ for $1-2 \mathrm{~min}$. Lysis was stopped by adding $30 \mathrm{ml}$ serum-free media to the suspension.

Screening of wells for ELISA reactivity against the small molecule/ KLH conjugates was done as previously described (for details, see Madl et al., 1986) using polystyrene microtiter plates coated overnight with the small molecule/KLH conjugate in $0.05 \mathrm{~m}$ carbonate buffer, $\mathrm{pH} 9.6$, at a concentration of $2 \mu \mathrm{g} \mathrm{KLH} / \mathrm{ml}$. Wclls were washed in PBS with $0.05 \%$ Tween 20 (Sigma) and then blocked with $1 \%$ BSA in PBS for 1 hr. After washing, culture supernatants were added to the wells for 90 min. After another wash series, affinity-purified, peroxidase-labeled goat anti-mouse antibody (Cappel, Malvern, PA) diluted 1:400 in PBS was added to the wells for $1 \mathrm{hr}$. After washing, $o$-phenylenediamine with hydrogen peroxide in a citrate buffer was added to the wells and the absorbance at $490 \mathrm{~nm}$ was read after 30 min incubation.

Cell lines from wells with supernatants that had high ELISA reactivity for the small molecule/KLH conjugate were expanded, and culture supernatants were tested for immunocytochemical staining of brain sections and for ELISA reactivity with other small molecule-containing conjugates. Cell lines producing antibody with strong and specific ELISA reactivity and the ability to stain tissue sections were frozen in liquid nitrogen, and representative ccll lines were subcloned by limiting dilution. Ascitic fluid was raised in Balb/c/umc mice of both sexes after pretreatment with $0.5 \mathrm{ml}$ pristane $(2,6,10,14$-tetramethyl-pentadecane, Sigma) intraperitoneally a week before intraperitoneal injection of $10^{\circ}$ hybridoma cells.
Detection of antibody activity by ELISA assay. Specificity testing of monoclonal antibodies by ELISA was done as previously descibed in detail in Madl et al. (1986) and was similar to the screening assays outlined in the previous section, with the following modifications. Conjugates of different small molecules with $\mathrm{KLH}$ at a concentration of 4 $\mu \mathrm{g} \mathrm{KLH} / \mathrm{ml}$ of coating buffer were used to coat the polystyrene plates overnight at $4^{\circ} \mathrm{C}$. Conjugates using BSA as the carrier protein were coated overnight at room temperature. Culture supernatants were used at a dilution of $1: 10$ in $0.1 \mathrm{M}$ PBS. Absorhance was read at 45 min after adding the substrate/chromogen solution.

Quantification of the inhibition of the antibodies' reactivity for $\beta$-AspAsp/KLH by various small molecules or conjugates was performed using a competitive inhibition ELISA assay (Friguet et al., 1985; Geffard et al., 1985; Madl et al., 1986). This assay was done as in the screening assays, except various amounts of small molecules or conjugates were added to a 1:250 dilution of Asp1 or Asp2, or to a 1:50 dilution of Asp 3 in PBS. These solutions were allowed to mix for 30 to $60 \mathrm{~min}$ for small molecules and at least $1 \mathrm{hr}$ for conjugates before adding to the wells.

Determination of the subisotype of the monoclonal antibody. Subisotyping was done using the mouse monoclonal subisotyping kit $55050-\mathrm{K}$ from HyClone Laboratories (Logan, Utah).

Immunocytochemistry. Immunocytochemical staining of tissue sections was done using an indirect immunoperoxidase staining procedure described in detail in Madl et al. (1986) or a biotin-avidin immunoperoxidase staining procedure described in Beitz et al. (1986a). Male rats were anesthetized and transfused transcardially with $50 \mathrm{ml}$ of calcium-free Tyrode's solution and subsequently fixed by perfusion with $50 \mathrm{ml}$ of one of the following: (1) $5 \%$ glutaraldehyde (Fisher, Minneapolis, MN) in PBS; (2) 4\% acrolein in PBS; (3) 4\% paraformaldehyde in $0.1 \mathrm{M}$ Sorenson's buffer; or (4) freshly made, $5 \%$ carbodiimide with $5 \%$ glutaraldehyde or $4 \%$ paraformaldehyde. Tissue was postfixed overnight in $5 \%$ glutaraldehyde, $4 \%$ paraformaldehyde, or $4 \%$ acrolein. Tissue sections $70 \mu \mathrm{m}$ thick were cut on a Vibratome (Oxford Labs, Foster City, CA) and were incubated in appropriate dilutions of the culture supernatants (generally 1:100) or ascitic fluid (generally 1:2000) in PBS containing $0.3 \%$ Triton X-100 (Sigma) for $1.5 \mathrm{hr}$.

For the indirect immunoperoxidase technique, after rinsing, tissue sections were incubated in a 1:100 dilution in PBS of affinity-purified, peroxidase-labeled goat anti-mouse antibody (Cappel) for $1 \mathrm{hr}$. After further rinsing, the sections were incubated in Tris buffer containing 3,3'-diaminobenzidine tetrahydrochloride (DAB) and hydrogen peroxide until sufficient staining was obtained (usually about $15 \mathrm{~min}$ ).

The Vectastain ABC kit (Vector Labs, Burlingame, CA) was used for the avidin-biotin staining procedure. After rinsing, the sections were incubated for $1 \mathrm{hr}$ in a 1:4 dilution in PBS of the recommended biotinylated anti-mouse antibody reagent. After further rinsing, the sections were incubated for $1 \mathrm{hr}$ in a 1:4 dilution in PBS of the recommended avidin-peroxidase complex reagent. After rinsing, the sections were incubated in a DAB-Tris solution containing hydrogen peroxide as described in Beitz et al. (1986a) until sufficient staining was obtained.

Sections were then mounted on gel-coated slides, dehydrated in graded ethanol solutions, cleared in xylene, and mounted in Permount.

Inhibition of tissue staining by small molecules. Culture supernatants at appropriate dilutions (usually $1: 100$ ) in PBS with $0.3 \%$ Triton X-100 were incubated with various concentrations of small molecules as previously described in Madl et al. (1986) beforc use in indirect immunoperoxidase tissue staining.

Inhibition of tissue staining by conjugates. Culture supernatants or ascitic fluid at appropriate dilutions were incubated with conjugates at a concentration of $1 \mathrm{mg} / \mathrm{ml}$ of KLH in PBS with $0.3 \%$ Triton X-100 for $30 \mathrm{~min}$ before use in either indirect immunoperoxidase or biotinavidin immunocytochemical staining.

\section{Results}

Results of initial screenings

Culture supernatants from 6 wells were strongly reactive $(>10$ times background) for $\beta$-Asp-Asp/KLH on ELISA of the 480 wells that were screened at days 12 and 16 postfusion. Cell lines were expanded from these 6 wells and culture supernatants from these lines proved capable of indirect immunopcroxidase staining of tissue sections fixed with carbodiimide and glutaralde- 
Table 1. Immunoreactivity of culture supernatants for conjugates assessed by ELISA

\begin{tabular}{lcccrc} 
& \multicolumn{6}{l}{ Immunoreactivity $^{b}$} \\
\cline { 2 - 6 } Conjugate $^{a}$ & Asp1 & Asp2 & Asp3 & GABAl $^{c}$ & CS1 $^{d}$ \\
\hline$\beta$-Asp-Asp/KLH & 0.971 & 0.955 & 0.770 & 0.014 & 0.029 \\
Asp/KLH & 0.044 & 0.027 & 0.293 & 0.015 & 0.531 \\
Cysteic acid/KLH & 0.001 & 0.017 & 0.046 & 0.013 & 0.606 \\
$\gamma$-Glu-Glu/KLH & 0.003 & 0.009 & 0.005 & 0.014 & 0.025 \\
GABA-GABA/ & & & & & \\
$\quad$ KLH & 0.000 & -0.003 & 0.001 & 0.215 & 0.007 \\
Glu/KLH & 0.008 & 0.008 & 0.007 & 0.016 & 0.538 \\
Cysteine sulfinate/ & & & & & \\
$\quad$ KLH & 0.000 & 0.009 & 0.004 & -0.003 & 0.045 \\
GABA/KLH & 0.005 & 0.000 & -0.001 & 0.024 & 0.223
\end{tabular}

${ }^{a}$ Conjugates made by coupling small molecules to $\mathrm{KLH}$ using glutaraldehydeborohydride. Plates were coated with conjugates at a concentration of $4 \mu \mathrm{g} / \mathrm{ml}$ KLH.

${ }^{b}$ Absorbance at $490 \mathrm{~nm}$ after subtraction of absorbance in control wells containing no primary antisera. Mean of 6 replicate wells. Largest SEM was 0.024 .

'Culture supernatant from a hybridoma produced from a mouse immunized with GABA-GABA/KLH

${ }^{d}$ Culture supernatant from a hybridoma produced from a mouse immunized with cysteine sulfinate/KLH.

hyde. Culture supernatants from the 6 cell lines were then evaluated for ELISA immunoreactivity with small molecules conjugated to KLH by glutaraldehyde-borohydride. Three of the culture supernatants-designated Asp1, Asp2, and Asp3reacted with $\beta$-Asp-Asp/KLH and not with $\gamma$-L-glutamyl-L-glutamate/KLH or $\gamma$-aminobutyryl- $\gamma$-aminobutyric acid/KLH (see Table 1). Two of the culture supernatants reacted with several conjugates. One culture did not continue to produce reactive supernatant. Cell lines producing Asp1-3 were subcloned by limiting dilution, and their culture supernatants were further examined for specificity. The isotypes of the monoclonal antibodies obtained after screening and subcloning were determined to be IgG1 for Aspl and Asp2 and IgM for Asp3.

\section{Evaluation of antibody specificity by ELISA}

\section{ELISA reactivity of antibodies for conjugates coated to plates}

Culture supernatants from the subclones were evaluated for their reactivity against small molecules conjugated to KLH using glutaraldehyde-borohydride (Table 1) and were found to have very similar immunoreactivities. Only the conjugates that contained $\beta$-Asp-Asp or aspartate coupled to the carrier protein reacted with the antibodies to a significant degree, except for some moderate reactivity of Asp3 for the conjugate containing cysteic acid. L-glutamate, $\gamma$-L-glutamyl-L-glutamate, and $\gamma$-aminobutyryl- $\gamma$-aminobutyric acid coupled to KLH by glutaraldehyde-borohydride had almost no measurable immunoreactivities. Immunoreactivities of Asp1-3 for KLH treated with glutaraldehyde-borohydride were also minimal. Immunoreactivities of 2 other monoclonal antibodies with very different specificities, CS1 and GABA1, are included in Table 1 to demonstrate that significant amounts of glutamate, aspartate, GABA, GABA-GABA, and cysteic acid were present in the conjugates used to coat the ELISA plates. Dilution of the $\beta$-Asp-Asp/KLH used to coat the ELISA plate (Fig. 1) or dilution of the culture supernatants (Fig. 2) resulted in a reduction in ELISA activity for all 3 monoclonal antibodies, consistent with specificity of the antibodies for the $\beta$-Asp-Asp/KLH coating the plate.

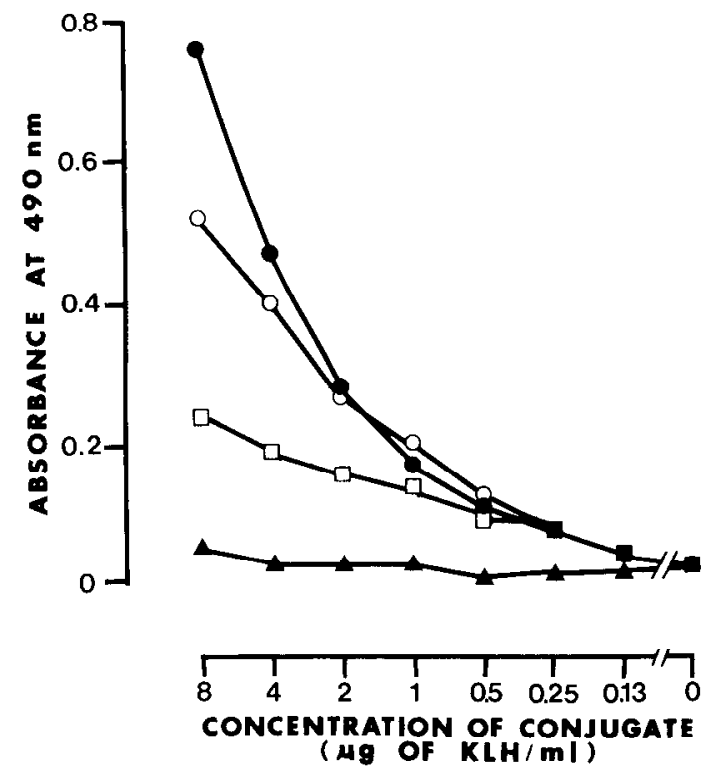

Figure 1. Immunoreactivity (absorbance at $490 \mathrm{~nm}$ ) of monoclonal antibodies for various concentrations of $\beta$-Asp-Asp/KLH used to coat the ELISA plate. Culture supernatants diluted 1:250 in PBS for Asp1 (solid circles) and Asp2 (open circles) and 1:50 in PBS for Asp3 (open squares). ELISA reactivity when no supernatants were added is indicated by the solid triangles. Each point represents an average of 4 replicates with a SEM of 0.024 absorbance units or less.

\section{Competitive inhibition of ELISA reactivity by small molecules}

Inhibition by small molecules of the binding of Asp 1-3 to $\beta$-AspAsp coupled to KLH using glutaraldehyde-borohydride was quantified (Table 2) by a competitive inhibition enzyme immunoassay. Results of inhibition of ELISA reactivity by small molecules of antibody Asp 1 for $\beta$-Asp-Asp/KLH are illustrated in Figure 3. Similar curves were obtained for Asp2. Reactivities of Asp1 and Asp2, both monoclonal antibodies of isotype IgG1, were inhibited by similar compounds but to different degrees (Table 3). All compounds that showed measurable inhibition of binding of the monoclonal antibodies for the $\beta$-Asp-Asp conjugate contained aspartic acid. Asp3, an antibody of isotype IgM, was not inhibited by small molecules at the concentrations used in this study.

\section{Competitive inhibition of ELISA reactivity by conjugates}

Inhibition by conjugates of the binding of Asp1-3 to $\beta$-Asp-Asp coupled to KLH using glutaraldehyde-borohydride was quantified (Table 4). Asp3 was inhibited at lower concentrations of the aspartate-containing conjugates than Asp1 or Asp2. Asp3 was also inhibited by cysteic acid conjugated to KLH. ELISA immunoreactivity of all 3 of the antibodies was inhibited in a concentration-dependent manner by preincubation of the antibodies with conjugates containing $\beta$-Asp-Asp or aspartate conjugated to $\mathrm{KLH}$ using glutaraldehyde-borohydride. Figure 4 shows inhibition curves for antibodies Aspl and Asp3. Curves similar to those shown for Asp1 were obtained for Asp2.

\section{ELISA reactivity of antibodies for conjugates made by different fixatives}

Small amounts of tritiated amino acids were added to conjugation reactions to quantitate the efficiency of conjugation of glutamic acid, aspartic acid, glycine, and taurine to BSA using 


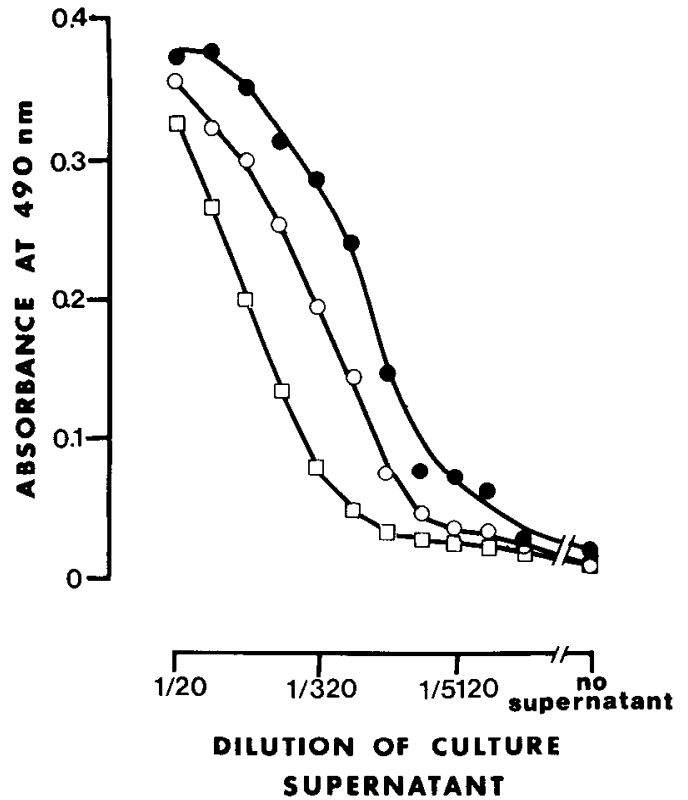

Figure 2. Immunoreactivity (absorbance at $490 \mathrm{~nm}$ ) of dilutions of the monoclonal antibodies for $\beta$-Asp-Asp/KLH $(2 \mu \mathrm{g} \mathrm{KLH} / \mathrm{ml})$ used to coat the ELISA plate. Culture supernatants from Asp1 (solid circles), Asp2 (open circles), and Asp3 (open squares) were diluted in PBS as indicated. Each point represents an average of 4 replicates.

either acrolein, glutaraldehyde, or paraformaldehyde. After dialysis, $0.127(\mathrm{SE}=0.016)$ of the amino acids were bound to BSA by glutaraldehyde, $0.036(\mathrm{SE}=0.001)$ of the amino acids were bound using acrolein and only $0.002(\mathrm{SE}=0.0001)$ were bound using paraformaldehyde.

ELISA reactivity of Asp1 and Asp3 for aspartate coupled to BSA using the above 3 aldehydes was quantified (Table 5). Asp 1

Table 2. Inhibition of antibody activity by small molecules

\begin{tabular}{|c|c|c|c|c|c|c|}
\hline \multirow[b]{2}{*}{ Compound } & \multicolumn{3}{|c|}{$\begin{array}{l}\text { Inhibition of } \\
\text { ELISA reactivity }\end{array}$} & \multicolumn{3}{|c|}{$\begin{array}{l}\text { Inhibition of } \\
\text { tissue staining }{ }^{b}\end{array}$} \\
\hline & Asp1 & Asp2 & Asp3 & Asp 1 & Asp 2 & Asp3 \\
\hline$\beta$-Asp-Asp & + & + & - & ++ & ++ & - \\
\hline N-Ac-Asp & ++ & + & - & ++ & ++ & - \\
\hline Gly-Asp & + & + & - & + & + & - \\
\hline N-Ac-Glu & - & - & - & - & - & - \\
\hline$\alpha$-Asp-Gly & - & - & - & - & - & - \\
\hline$\beta$-Asp-Gly & - & - & - & - & - & - \\
\hline$\gamma$-Glu-Glu & - & - & - & - & - & - \\
\hline N-Me-Asp & - & - & - & - & - & - \\
\hline N-Me-Glu & - & - & - & - & - & - \\
\hline Gly-Glu & - & - & - & - & - & - \\
\hline GABA-GABA & & $\cdots$ & - & - & - & - \\
\hline Gly-GABA & - & - & - & - & - & - \\
\hline GABA & - & - & - & - & - & - \\
\hline Asp & - & - & - & - & - & - \\
\hline Glu & - & - & - & - & - & - \\
\hline Cysteic acid & - & - & - & - & - & - \\
\hline
\end{tabular}

"Reduction in ELISA reactivity for $\beta$-Asp-Asp conjugated to KLH using glutaraldehyde-borohydride after inhibition with $2.5 \mathrm{~mm}$ of the compound: ++ , $>80 \%$ reduction in reactivity;,$+>20 \%$ reduction in reactivity;,$-<20 \%$ reduction in reactivity.

${ }^{b}$ Reduction in intensity of tissue staining after inhibition with $2.5 \mathrm{~mm}$ of the compound: ++ , greatly reduced; + , moderately reduced; - , minimally reduced.

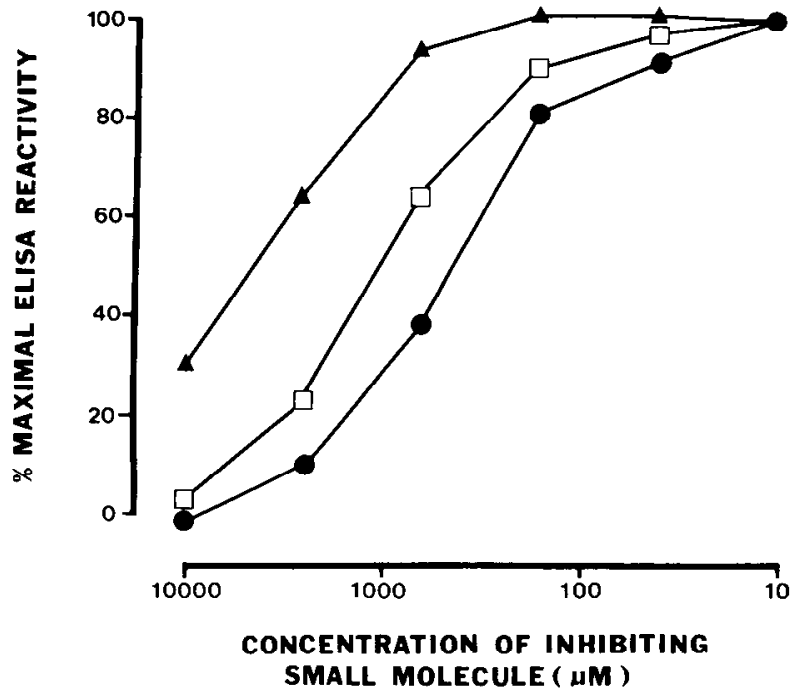

Figure 3. Inhibition by small molecules of Asp1 antibody immunoreactivity (absorbance at $490 \mathrm{~nm}$ ) for $\beta$-Asp-Asp/KLH. Culture supernatant diluted 1:250 in PBS. N-acetyl-Asp (solid circles); $\beta$-Asp-Asp (open squares); Gly-Asp (solid triangles). Each point reprcsents an average of 4 replicates with a SEM of $9 \%$ or less.

and Asp3 were inhibited in a concentration-dependent manner by preincubation of the antibodies with amino acids coupled to BSA using acrolein (Table 6). The aspartate-containing conjugate was able to inhibit the monoclonal antibodies at a much lower concentration than the conjugates containing other amino acids. Figure 5 shows inhibition curves for Asp1 by aspartate coupled to BSA using acrolein, glutaraldehyde, and paraformaldehyde.

\section{Evaluation of tissue staining \\ Effects of fixation}

Strong immunocytochemical staining of tissue by Asp 1-3 was seen when the tissue was fixed with glutaraldehyde, acrolein, or a combination of either of these aldehydes with carbodiimide. Asp 1-3 produced no staining of cell bodies or dendrites in tissue fixed with paraformaldehyde alone or a combination of paraformaldehyde with carbodiimide. Fixation with acrolein resulted in a more selective pattern of staining. In contrast, the monoclonal antibody with a high degree of specificity for glutamate-containing molecules, Glu1, described in Madl et al

\section{Table 3. IC $_{50}$ and cross-reactivity of small molecules on ELISA}

\begin{tabular}{|c|c|c|c|c|c|c|}
\hline \multirow[b]{2}{*}{ Compound } & \multicolumn{2}{|l|}{ Asp1 } & \multicolumn{2}{|l|}{ Asp2 } & \multicolumn{2}{|l|}{ Asp3 } \\
\hline & $\begin{array}{l}\mathrm{IC}_{50}{ }^{a} \\
(\mathrm{mM})\end{array}$ & $\begin{array}{l}\mathrm{CR}^{b} \\
(\%)\end{array}$ & $\begin{array}{l}\mathrm{IC}_{\mathrm{s0}} \\
(\mathrm{mM})\end{array}$ & $\begin{array}{c}\mathrm{CR} \\
(\%)\end{array}$ & $\begin{array}{l}\mathrm{IC}_{\mathrm{s0}} \\
(\mathrm{mM})\end{array}$ & $\begin{array}{c}\text { CR } \\
(\%)\end{array}$ \\
\hline N-Ac-Asp & 0.4 & 100 & 0.9 & 100 & $>10$ & $\mathrm{ND}^{c}$ \\
\hline$\beta$-Asp-Asp & 1.0 & 40 & 0.9 & 100 & $>10$ & ND \\
\hline Gly-Asp & 4.5 & 9 & 2.0 & 45 & $>10$ & ND \\
\hline$\beta$-Asp-Gly & $>10$ & $<4$ & $>10$ & $<9$ & $>10$ & ND \\
\hline
\end{tabular}

${ }^{a} \mathrm{IC}_{50}$, concentration producing $50 \%$ inhibition of ELISA reactivity for $\beta$-Asp-Asp conjugated to KLH using glutaraldehyde-boruhydride.

${ }^{b} \mathrm{CR}$, percentage cross-reactivity was determined from the ratios of the $\mathrm{IC}_{50}$ values of the most inhibitory small molecule for each antibody with the various small molecules.

cND; not determinable with the concentrations used in these studies. 


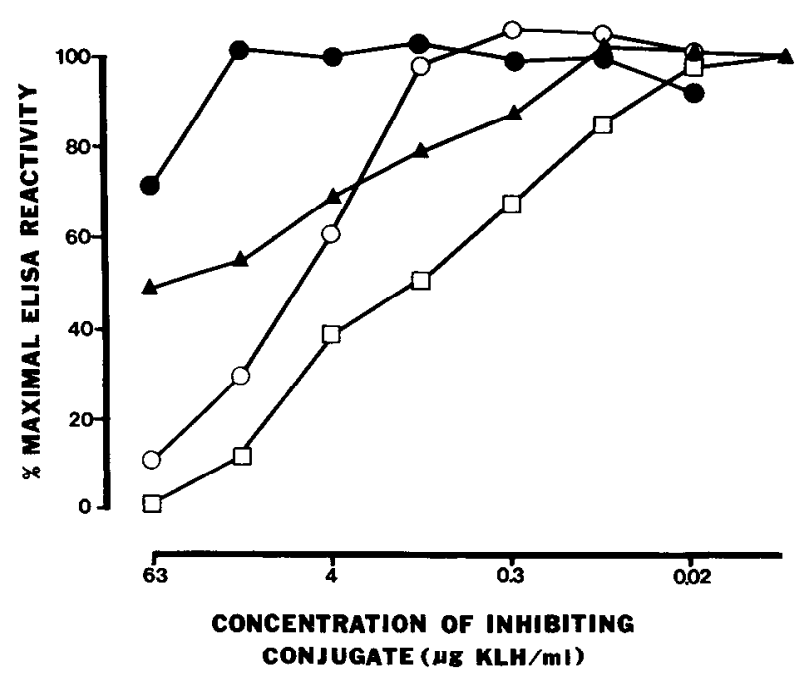

Figure 4. Inhibition by conjugates of Aspl and Asp3 antibody immunoreactivity (absorbance at $490 \mathrm{~nm}$ ) for $\beta$-Asp-Asp/KLH. Culture supernatants diluted 1:250 in PBS for Asp1 and 1:50 in PBS for Asp3. Beta-Asp-Asp/KLH inhibition of Asp1 (open circles) and Asp3 (open squares); Asp/KLH inhibition of Aspl (solid circles) and Asp3 (solid triangles). Each point represents an average of 4 replicates with a SEM of $5 \%$ or less.

(1986), was found to give staining of tissue perfused with either paraformaldehyde, glutaraldehyde, or acrolein when the biotinavidin staining procedure was used.

\section{Staining of selected CNS regions}

Preliminary data indicate that Asp1-3 gave similar patterns of staining of neuronal cell bodies, dendrites, and fibers in the regions of the CNS examined in the present study. When glutaraldehyde was used to fix the tissue, the nuclei of many neurons were intensely stained. This nuclear staining was greatly reduced following acrolein fixation. In addition, when acrolein was used to fix the tissue, a more selective staining pattern was observed than when glutaraldehyde was used. Staining was absent from neuroglial cells in either acrolein- or glutaraldehyde-fixed tissue.

Cerebral cortex. Despite overall similarities, the pattern of aspartate-like immunoreactivity found in the cerebral cortex displayed clear differences in certain cortical regions from the pattern previously described for glutamate-like immunoreactivity by Madl et al. (1986). For example, when a high concentration of Asp1-3 was used for staining either glutaraldehydeor acrolein-fixed tissue, moderately intense staining of cell bodies and dendrites of neurons was seen in layers 2-6 of the cerebral cortex in certain cortical areas such as area 18 of the visual cortex (Fig. 6A). In contrast, Glu 1 stains primarily pyramidal

Table 4. $I_{50}$ of glutaraldehyde-borohydride conjugates on ELISA

\begin{tabular}{|c|c|c|c|}
\hline \multirow{2}{*}{$\begin{array}{l}\text { Small molecules/ } \\
\text { protein conjugate }\end{array}$} & \multicolumn{3}{|l|}{$\mathrm{IC}_{50}{ }^{a}$} \\
\hline & Asp1 & Asp2 & Asp3 \\
\hline$\beta$-Asp-Asp/KLH & 7 & 12 & 1.2 \\
\hline Asp/KLH & 222 & $>250$ & 47 \\
\hline cysteic acid/KLH & $>250$ & $>250$ & 40 \\
\hline Glu/KLH & $\gg 250$ & $\gg 250$ & $\gg 250$ \\
\hline KLH & $\gg 250$ & $\gg 250$ & $\gg 250$ \\
\hline
\end{tabular}

${ }^{a} \mathrm{IC}_{50}$, micrograms of $\mathrm{KLH} / \mathrm{ml}$ producing $50 \%$ inhibition of ELISA reactivity.

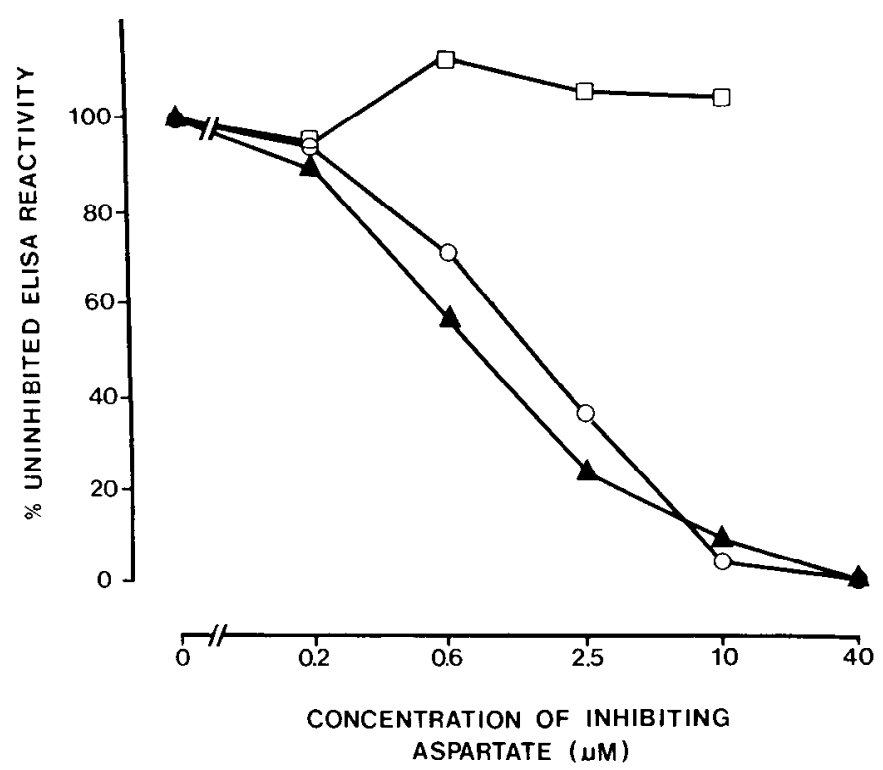

Figure 5. Inhibition by conjugates of Aspl antibody immunoreactivity (absorbance at $490 \mathrm{~nm}$ ) for Asp/BSA conjugates made with glutaraldehyde (open circles), acrolein (solid triangles), or paraformaldehyde (open squares). Each point represents the average of 3 replicate wells with a SEM of $4.6 \%$ or less. Plates were coated with Asp/BSA conjugated with acrolein at $4 \mu \mathrm{g} \mathrm{BSA} / \mathrm{ml}$. Aspl ascitic fluid was diluted 1:1000 in PBS.

cells of layer 3 of area 18 . In some regions of the cerebral cortex, such as area $18 \mathrm{a}$, neurons in only layer 3 were stained with Asp1-3, while no neuronal staining was evident in this region with Glul. In other regions, such as auditory cortex and motor cortices, only neurons in layers 5 and 6 were stained with Asp13. Intense neuronal staining was also evident in the primary olfactory cortex.

Cerebellum. Within the cerebellar cortex, when glutaraldehyde was used as the fixative, staining was observed in basket cells and stellate cells. No staining was seen in Purkinje cells (Fig. 7). An interesting heterogeneic staining pattern was evident in the granule cell layer. Immunoreactivity was present in small clusters of granule cells, while other granule cells had minimal staining. However, following acrolein fixation, diffuse staining occurred in the molecular layer of the cerebellar cortex, but no perikaryal staining was evident in cerebellar cortex at similar concentrations of the antibodies (Fig. 8). Intense staining of some neurons in the deep cerebellar nuclei was evident in either acrolein- or glutaraldehyde-fixed tissue.

Hippocampus. When glutaraldehyde was used to fix the tissue, intense staining of some pyramidal cell bodies and dendrites of the hippocampus was observed (Fig. 9). These neurons were not

Table 5. ELISA reactivity ${ }^{a}$ of aspartic acid/BSA conjugates made using different fixatives

\begin{tabular}{llll}
$\begin{array}{l}\text { Conjugation } \\
\text { procedure }\end{array}$ & Asp1 & Asp2 & Asp3 \\
\hline Glutaraldehyde & 0.032 & 0.014 & 0.030 \\
Acrolein & 0.294 & 0.134 & 0.296 \\
Paraformaldehyde & 0.012 & 0.009 & 0.010
\end{tabular}

${ }^{a}$ Absorbance at $490 \mathrm{~nm}$. Mean of 6 replicate wells. SEM was 0.007 or less. Plates were coated at room temperature with $3 \mu \mathrm{g}$ of $\mathrm{BSA} / \mathrm{ml}$. 

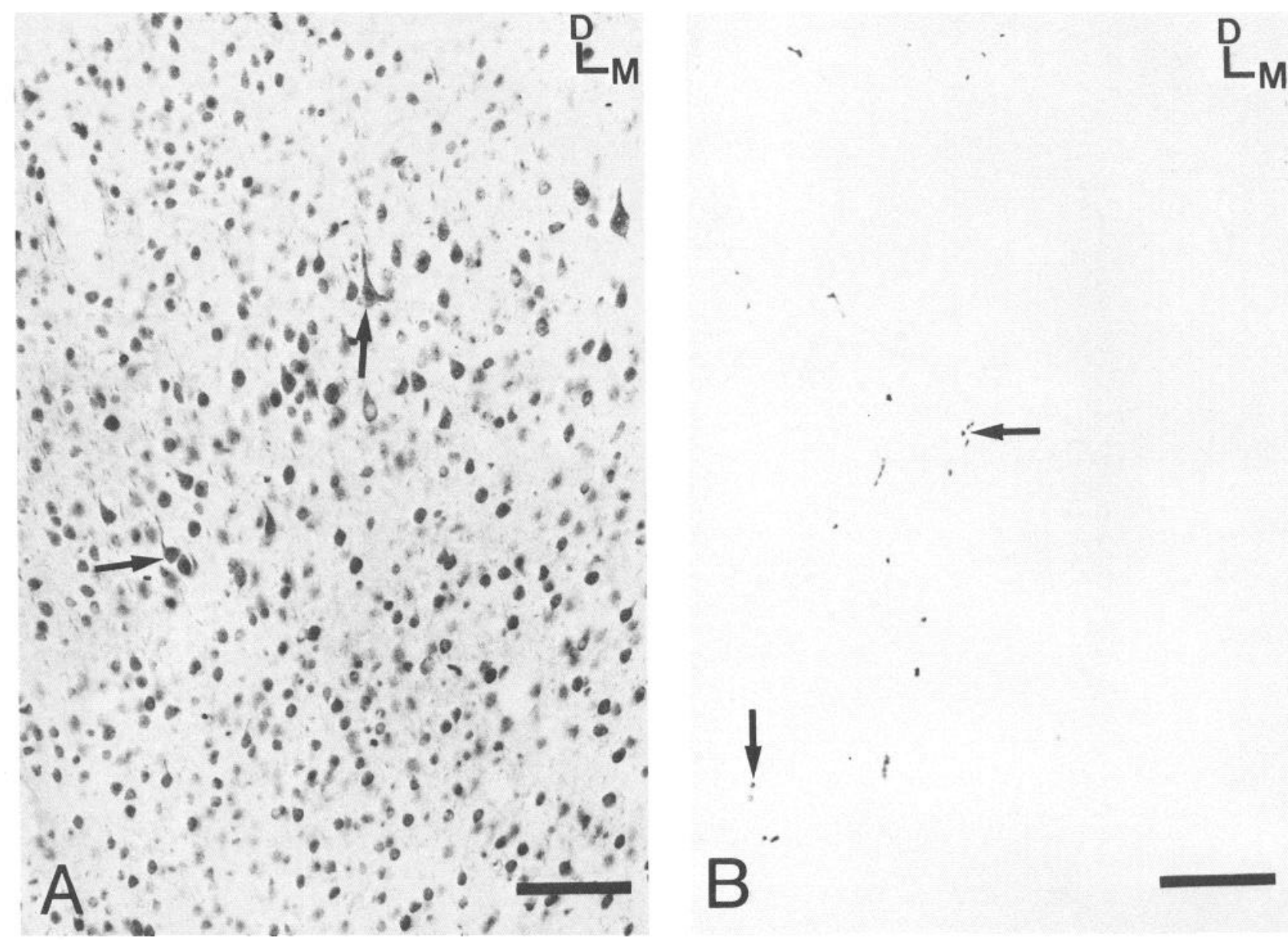

Figure 6. Indirect immunoperoxidase staining of frontal sections of rat cerebral cortex by Aspl in culture supernatant. $A$, Intense staining of neuronal cell bodies in layers $2-6$ from area 18 of the visual cortex. Immunoreactive pyramidal cells are indicated by arrows. $B$, Inhibition of staining of cortical cells by $2.5 \mathrm{~mm} \mathrm{~N}$-AcAsp. Arrows indicate red blood cells with endogenous peroxidase activity. Tissue was fixed with carbodiimide and glutaraldehyde. Scale bar, $100 \mu \mathrm{m}$. $D$, dorsal; $M$, medial.

stained at similar concentrations of antibody when acrolein was used for tissue fixation.

Other regions. Aspartate-like immunoreactivity was evident in several brain stem nuclei. Following either acrolein or glutaraldehyde fixation, intense neuronal staining was observed in the spinal trigeminal nucleus, nucleus of the trapezoid body, and certain reticular nuclei. Intense staining of the neuropil was evident in the facial nucleus, the trigeminal motor nucleus and the interpeduncular nucleus. With glutaraldehyde fixation, intense staining of neurons comprising the inferior olivary nucleus was observed (Fig. 10). Immunoreactive neurons were also evident in the dorsal horn of the spinal cord (Fig. 11A) and in the

Table 6. $\mathrm{IC}_{50}$ of acrolein conjugates on ELISA

\begin{tabular}{lcc} 
Small molecules/ & $\mathrm{IC}_{\text {so }}{ }^{a}$ & \\
\cline { 2 - 3 } protein conjugate & Asp1 & Asp3 \\
\hline Asp/BSA & 1.3 & 10 \\
Glu/BSA & 160 & $>160$ \\
Gly/BSA & 110 & $>160$ \\
Tau/BSA & 55 & $>160$
\end{tabular}

${ }^{a} \mathrm{IC}_{50}$, concentration of amino acid $(\mu \mathrm{M})$ producing $50 \%$ inhibition of ELISA reactivity. cochlear nuclei. Intense staining of many fibers was seen in the inferior cerebellar peduncle and medial longitudinal fasciculus. Less intense staining of some fibers of the corpus callosum and anterior commissure was also evident.

\section{Evaluation of tissue staining specificity by absorption controls}

The same small molecules that were used in the competitive inhibition enzyme immunoassays were also used to determine their relative ability to inhibit indirect immunoperoxidase staining (Table 2) of glutaraldehyde and glutaraldehyde/carbodiimide fixed tissue. No difference was seen between tissue fixed with glutaraldehyde and glutaraldehyde/carbodiimide in the ability of small molecules to inhibit tissue staining. The results of these experiments indicate that compounds that inhibit the reactivity of the monoclonal antibodies on ELISA also inhibited the intensity of staining on brain tissue sections. In addition, the relative ability of these compounds to inhibit tissue staining was correlated with their ability to inhibit the monoclonal antibody-conjugate reaction on ELISA (Table 3). Beta-Asp-Asp and $N$-acetylaspartic acid were found to be the most effective inhibitors and were the only compounds capable of greatly reducing tissue staining by Asp1 and Asp2 in millimolar concentrations (Fig. $6 B$ ). No immunostaining was observed after elimination of either the monoclonal antibodies or secondary 
antibodies. Conjugates of $\beta$-Asp-Asp or aspartic acid to KLH using glutaraldehyde-borohydride were also capable of inhibiting tissue staining of Asp1-3 at a concentration of $0.2 \mathrm{mg}$ of $\mathrm{KLH} / \mathrm{ml}$ (Fig. 11B).

\section{Discussion}

Specificity of the monoclonal antibody

The results of 3 types of ELISA assay confirm that Asp1-3 have high degrees of specificity for aspartate-containing molecules produced by aldehyde fixation of aspartate to proteins. These monoclonal antibodies also have immunoreactivity for peptides with a carboxy-terminal aspartate. This is evidenced by the immunoreactivity of the antibodies for conjugates containing glutaraldehyde-borohydride-conjugated $\beta$-aspartyl-aspartate or aspartate, in contrast to very low immunoreactivities for other conjugates containing glutamate or GABA in similar configurations (Table 1). Some immunoreactivity of Asp3 for conjugates containing aldehyde-fixed cysteic acid was observed. Two types of competitive inhibition ELISA assays, which indicate the affinity of antibodies for small molecules or conjugates in solution (Nieto et al., 1984; Friguet et al., 1985), also suggest a high degree of specificity of the monoclonal antibodies for aldehyde- or carbodiimide-fixed aspartate or peptides with a carboxy-terminal aspartate. In the first type of inhibition assay, conjugates containing aldehyde-fixed aspartate were found to inhibit Asp1-3 at much lower concentrations than similar conjugates containing aldehyde-fixed glutamate or aldehyde-fixed GABA. In the second type of inhibition assay, free small molecules containing aspartate were demonstrated to inhibit Asp1 and Asp2, while similar free small molecules containing glutamate and GABA were shown not to inhibit Asp1-3 at the concentrations used in the studies. Inhibition ELISA assays are often more useful than direct immunoassays in quantifying crossreactivity of antibodies for various compounds because immunoreactivity of substances over a wide range of concentrations can be easily quantified (see, for example, Geffard et al., 1985; Madl et al., 1986). By using conjugates in the inhibition assays, one can more closely approximate the numerous possible modifications of the molecules of interest in tissue after reaction with fixatives. However, to confirm the specificity of the antibodies for particular molecules, such as $\beta$-Asp-Asp, it is preferable to use chemically pure small molecules in these inhibition assays.

At least 2 possibilities could account for the inability of free small molecules to inhibit Asp3 ELISA reactivity when conjugates of these same molecules do inhibit Asp3 ELISA reactivity. The first possibility is that the epitope recognized by the monoclonal antibody may be larger than the free small molecules used for inhibition and that after these small molecules are conjugated to the carrier protein they become more immunoreactive and are therefore able to inhibit the Asp3 ELISA reaction. The second possible explanation of the lack of inhibition by free small molecules of Asp3 involves the dependence of the functional affinity of antibodies on the number of sites on each antibody molecule at which binding occurs (Lew, 1984; as reviewed by Steward and Lew, 1985). We hypothesize that Asp3, an IgM with 10 binding sites, binds better to aspartic acid conjugated to carrier proteins than to small molecules containing aspartic acid because of multivalent interactions with these conjugates as well as increased size of the antigenic determinant found in the conjugate.

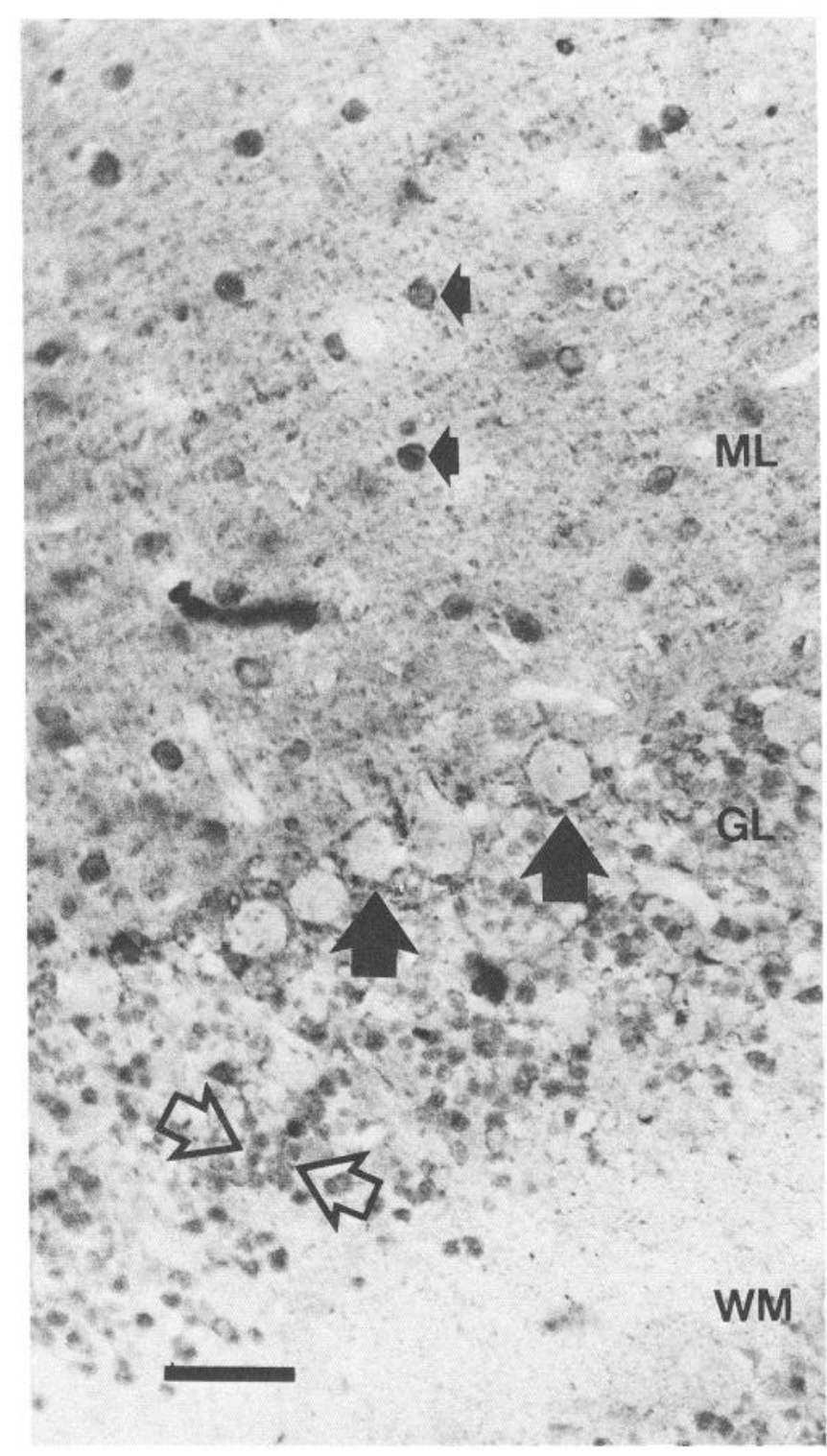

Figure 7. Biotin-avidin immunoperoxidase staining of frontal sections of the rat cerebellum by Aspl in ascitic fluid diluted 1:2000. Tissue was fixed with carbodiimide and glutaraldehyde. Within the molecular layer $(M L)$, stellate cells (small arrows) show intense staining. Purkinje cell bodies (large arrows) are unstained. Patches of granule cells, one of which is indicated between open arrows, in the granule cell layer $(G L)$ show intense immunoreactivity. White matter $(W M)$ is also indicated. Scale bar, $50 \mu \mathrm{m}$.

\section{Specificity of the immunocytochemical staining}

The immunocytochemical staining of rat CNS by monoclonal antibodies Asp1-3 can be inhibited by conjugates of aldehydefixed aspartate or $\beta$-aspartyl-aspartate for all 3 monoclonal antibodies. Staining of tissue by Aspl and Asp 2 can also be inhibited by free $\beta$-Asp-Asp and $N$-acetylaspartate at millimolar concentrations and by other aspartate-containing compounds at higher concentrations. This ability of aspartate-containing molecules to compete with immunoreactive substances in the tissues supports the concept that these monoclonal antibodies stain regions of the CNS containing fixative-modified aspartate in an immunoreactive configuration. The concept that Asp1-3 stain fixative-modified aspartate is further strengthened by the 
Figure 8. Biotin-avidin immunoperoxidase staining of a frontal section of the rat cerebellum by Aspl in ascitic fluid diluted 1:2000. Tissue was fixed with acrolein. $A$, Only faint, diffuse staining of neuropil is seen in the molecular layer $(M)$. B, Arrows indicate intensely stained neurons of the interpositus $(I)$ and lateral $(L)$ deep cerebellar nuclei. $D$, dorsal; $M$, medial. Scale bar, $100 \mu \mathrm{m}$.
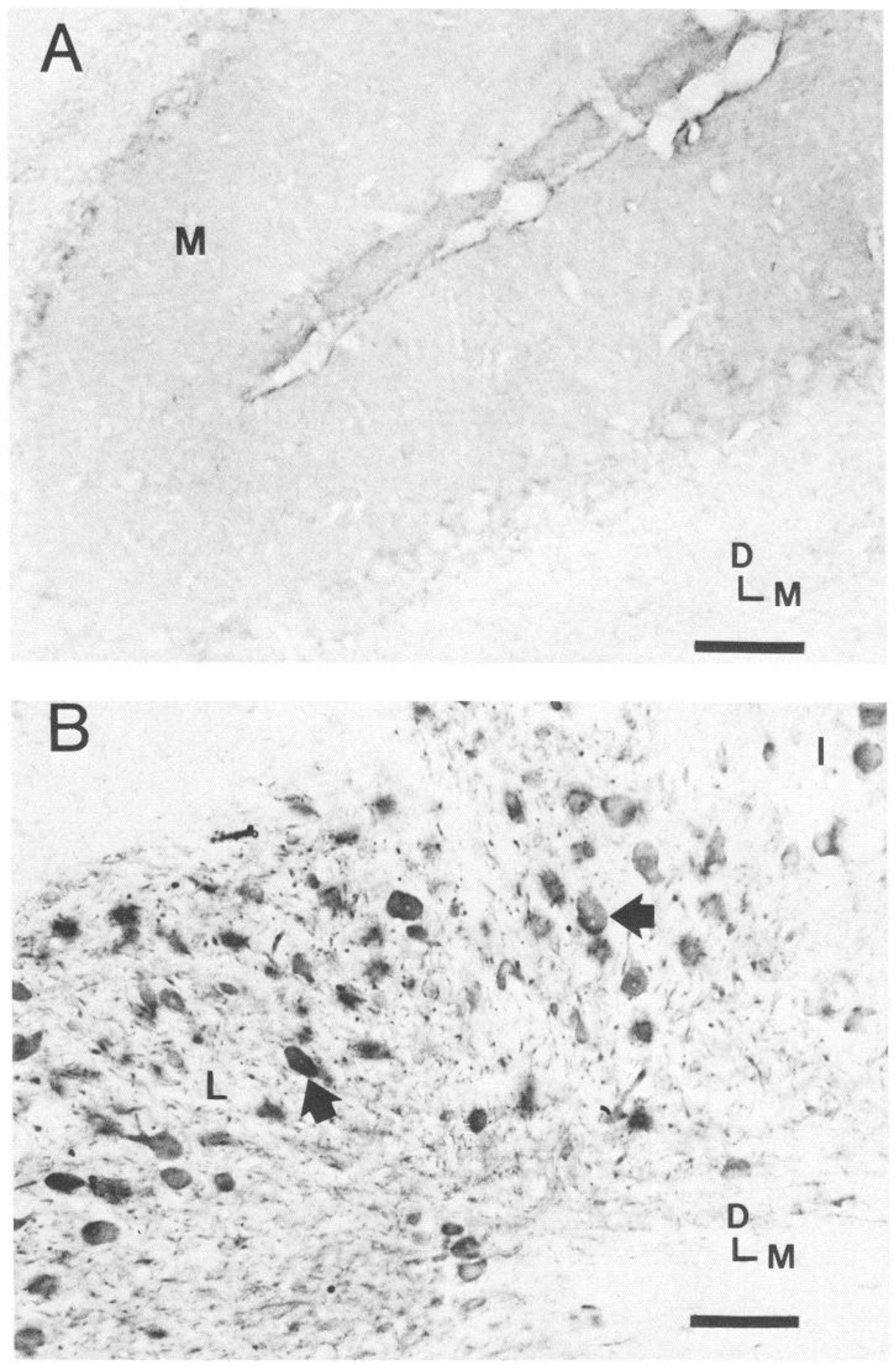

similarity of the tissue staining patterns of all 3 monoclonal antibodies despite their different degrees of affinity for aspartatecontaining conjugates and small molecules.

Tissues were found to be immunoreactive with Asp1-3 when fixed with glutaraldehyde, acrolein, and glutaraldehyde/carbodiimide, but not with paraformaldehyde or paraformaldehyde/ carbodiimide, suggesting that the immunoreactive modification of aspartate can be produced by glutaraldehyde or acrolein but not paraformaldehyde. These results are consistent with the ELISA findings that aspartate could be coupled by glutaraldehyde or acrolein to carrier proteins to form immunoreactive conjugates while reaction with paraformaldehyde did not form immunoreactive conjugates. This dependence of immunoreactivity of Asp1-3 on the type of fixation is in contrast to the independence of staining from type of fixation of the antibody Glu1. This suggests that the modifications of the aspartate molecule recognized by Asp1-3 are quite different from the modifications of glutamate or glutamate-containing molecules that allow recognition by Glu1. It had been noted previously (Madl et al., 1986) that only certain types of fixation protocols would give strong indirect immunoperoxidase staining with Glul. However, by intensifying the staining through use of the biotin- 


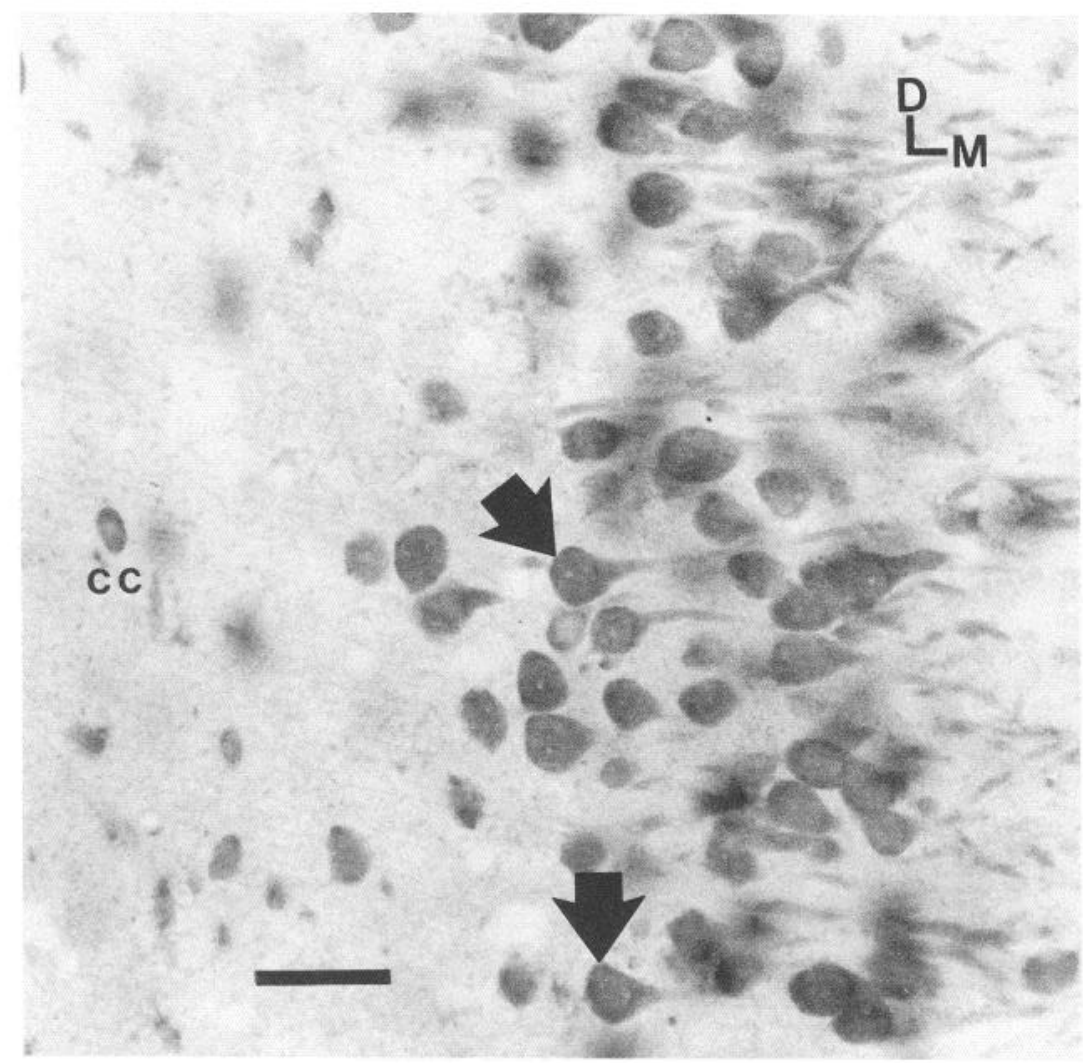

Figure 9. Indirect immunoperoxidase staining of frontal sections of the CA1 region of the hippocampus by Asp1. Pyramidal cells (arrows) and dendrites show intense immunoreactivity. $c c$, corpus callosum. Tissue was fixed with carbodiimide and glutaraldehyde. $D$, dorsal; $M$, medial. Scale bar, $50 \mu \mathrm{m}$.

avidin procedure, we were able to produce staining using any of the above fixatives.

\section{Correlation with other means of localizing aspartate}

Less than 2-fold differences in the concentration of aspartate have been reported between cortex, striatum, midbrain, and pons-medulla of the rat (Nicklas and Berl, 1973; Kimes and Shellenberger, 1983). Highest concentrations were reported for the cerebral cortex. Within the cerebral cortex of the rat, significantly higher concentrations of aspartate have been reported in the frontal cortex (Peinado et al., 1984). A comprehensive study of aspartate concentrations in rat CNS has recently been published by Palkovits and coworkers (1986). In agreement with the above studies, Palkovits et al. reported high concentrations of aspartate throughout the cerebral cortex. The highest concentration of aspartate was found in the pyriform cortex. This is in agreement with the staining pattern of aspartate-like immunoreactivity observed in the pyriform cortex in the present study, which found a large number of intensely immunoreactive neurons to be present. Immunoreactive neurons were also observed in other cortical regions, which is consistent with the data obtained by Palkovits et al. (1986). Intense immunocytochemical staining was also observed in several brain-stem regions also reported to contain high concentrations of aspartate (Palkovits et al., 1986). Within the midbrain, very intense neuropil staining was observed in the interpeduncular nucleus, which contained the highest midbrain concentration of aspartate. Palkovits et al. also reported high concentrations of aspartate in the facial nucleus, the inferior olive, and the sensory trigeminal complex. We found intense neuronal staining in the inferior olive and the sensory trigeminal nucleus, while the neuropil was intensely stained in the facial nucleus. In general, our immunocytochemical results are consistent with the biochemical data available in the literature.

Recently 2 reports of immunocytochemical localization of aspartate-like immunoreactivity have been published (Ottersen and Storm-Mathisen, 1985; Campistron et al., 1986). These studies used purified antisera raised against aspartate conjugated to carrier proteins using glutaraldehyde or glutaraldehyde-borohydride. In general, our results are in agreement with those reported, including the finding of aspartate-like immunoreactivity in putative GABAergic neurons in glutaraldehyde-fixed tissue as originally described in Ottersen and Storm-Mathisen (1985). A recent report by Toomim and coworkers (1986) indicated that antisera raised to glutaraldehyde-fixed aspartate and glutamate had cross-reactivity for dipeptides with carboxy-terminal aspartate or glutamate. The present results indicate the monoclonal antibodies also exhibit immunoreactivity for dipeptides containing a carboxy-terminal aspartate. This suggests that antibodies raised to amino acids conjugated by aldehyde fixatives may cross-react with peptides containing the amino acid in the carboxy-terminal position. Conversely, antibodies to oligopeptides may have substantial cross-reactivity with aldehyde-fixed amino acids. It may therefore be important that antisera used for immunocytochemical localization of amino acids be evaluated for cross-reactivity to peptides containing these amino acids.

High-affinity uptake of radiolabeled excitatory amino acids has been reported in many areas of the rat CNS (Divac et al., 1977; Fonnum, 1984). Although regions with increased amounts of high-affinity uptake may reflect areas where aspartate is being used for neurotransmission, glutamate can apparently be taken 


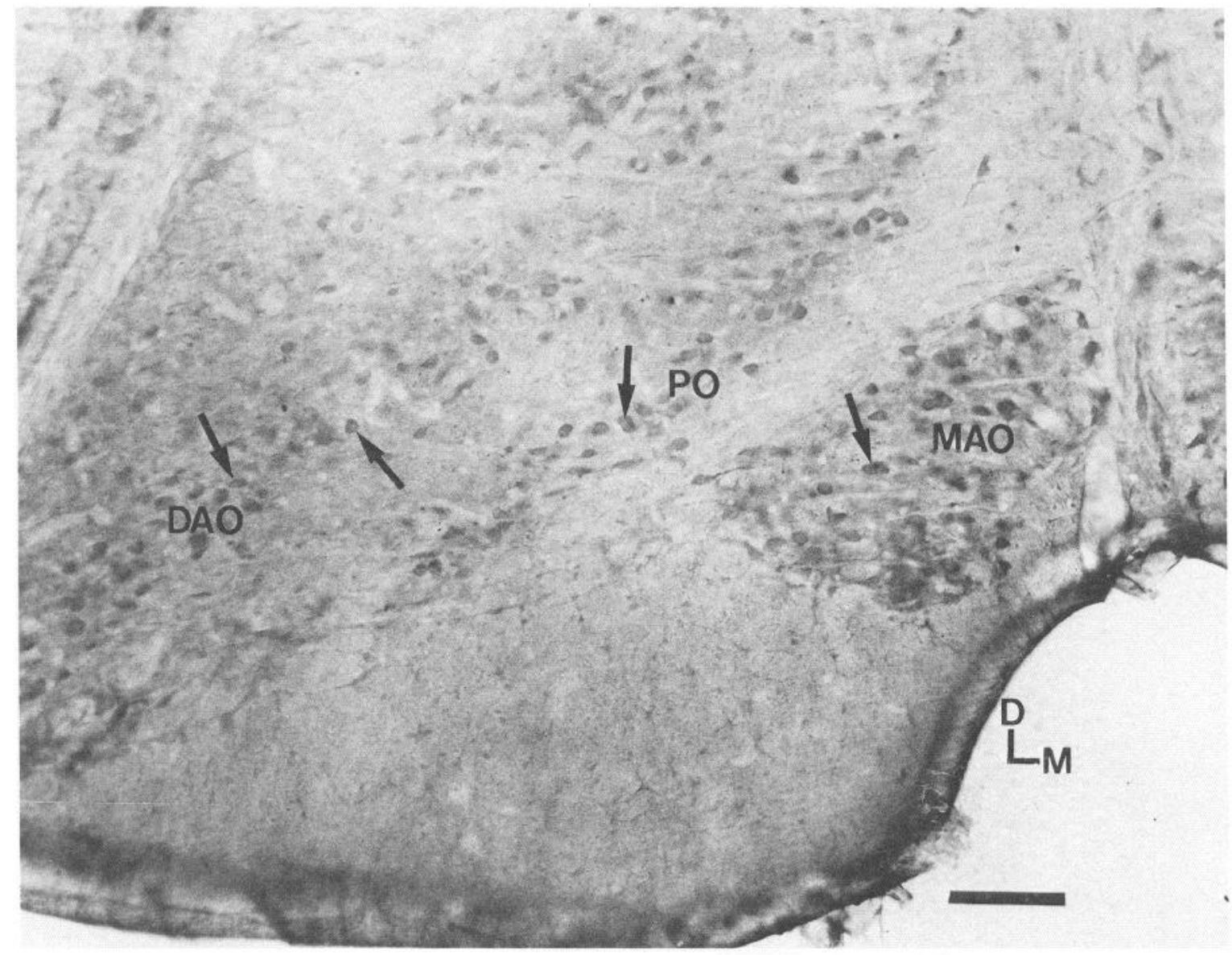

Figure 10. Biotin-avidin staining of rat inferior olivary nucleus with Asp2 in ascitic fluid diluted 1:2000. Immunoreactive neurons (arrows) are evident in all subdivisions of this nucleus. $M A O$, medial accessory olivary nucleus; $P O$, principal olivary nucleus; $D A O$, dorsal accessory olivary nucleus. Tissue was fixed with carbodiimide and glutaraldehyde. $D$, dorsal; $M$, medial. Scale bar, $100 \mu \mathrm{m}$.

up by these same sites (Fonnum, 1984), and therefore regions with increased uptake could also be indicative of areas where glutamate is used for neurotransmission. There is good agreement of intensity of aspartate-like immunoreactivity and the degree of high-affinity uptake of excitatory amino acids in areas we have investigated. For example, high-affinity uptake studies provide strong evidence indicating that glutamate and/or aspartate are putative neurotransmitters of cerebral cortical neurons (Young et al., 1981; Streit, 1985). The results of the present study are consistent with the hypothesis that aspartate serves as a neurotransmitter in certain cortical pyramidal neurons.

Aspartate aminotransferase (AATase), an enzyme that is capable of converting glutamate to aspartate or aspartate to glutamate, has been localized by immunocytochemistry in various areas of the rat CNS. AATase-like immunoreactivity has been proposed as a marker for neurons that use excitatory amino acids for neurotransmission. AATase-like immunoreactivity is found in all layers of the cerebral cortex (Donoghue et al., 1985) and is present in stellate cells of the cerebellar cortex (Wenthold and Altschuler, 1983). Asp1-3 do not stain as many cerebral cortical neurons as does the antisera raised against AATase, but staining of stellate cells in the cerebellar cortex is prominent with these monoclonal antibodies on glutaraldehyde-fixed tissue, suggesting that some neurons with greater concentrations of AATase also contain increased amounts of aspartate. As originally hypothesized by Wenthold et al. (1986) and discussed below, this possible anatomical correlation of AATase with large amounts of aspartate suggests that the aspartate in some of these neurons may be converted to glutamate and perhaps eventually to GABA.

The neurons of the inferior olivary nucleus have been proposed to use aspartate as a neurotransmitter on the basis of their release of endogenous aspartate upon stimulation by $\mathrm{K}^{+}$in cerebellar slices (Toggenburger et al., 1983) and because of their selective retrograde labeling by $\mathrm{D}-{ }^{-3} \mathrm{H}$-aspartate (Wiklund et al., 1984). In agreement with these reports, neurons in the olivary nucleus were found to contain aspartate-like immunoreactivity when glutaraldehyde was used as a fixative.

Preliminary studies suggest that Asp1-3 immunoreactivities are colocalized with Glul immunoreactivity in some neurons (Beitz et al., 1986b). This may explain why some similarities exist in the staining patterns produced by Asp1-3 and Glu1. However, many differences are apparent in the staining patterns produced by Asp1-3 as compared to Glul. This is especially apparent in the cerebellum, where Glul stains only granule cells. On the other hand, Asp1-3 stain some granule cells but also stellate and basket cells in glutaraldehyde-fixed tissue. Asp1-3 also intensely stain the nuclei of many neurons in glutaraldehyde-fixed tissue, while Glul does not. Similar staining of nuclei with antisera to glutamate, aspartate, and GABA have been reported in glutaraldehyde-fixed tissue by Storm-Mathisen et al. (1983) and Ottersen and Storm-Mathisen (1985). It should 

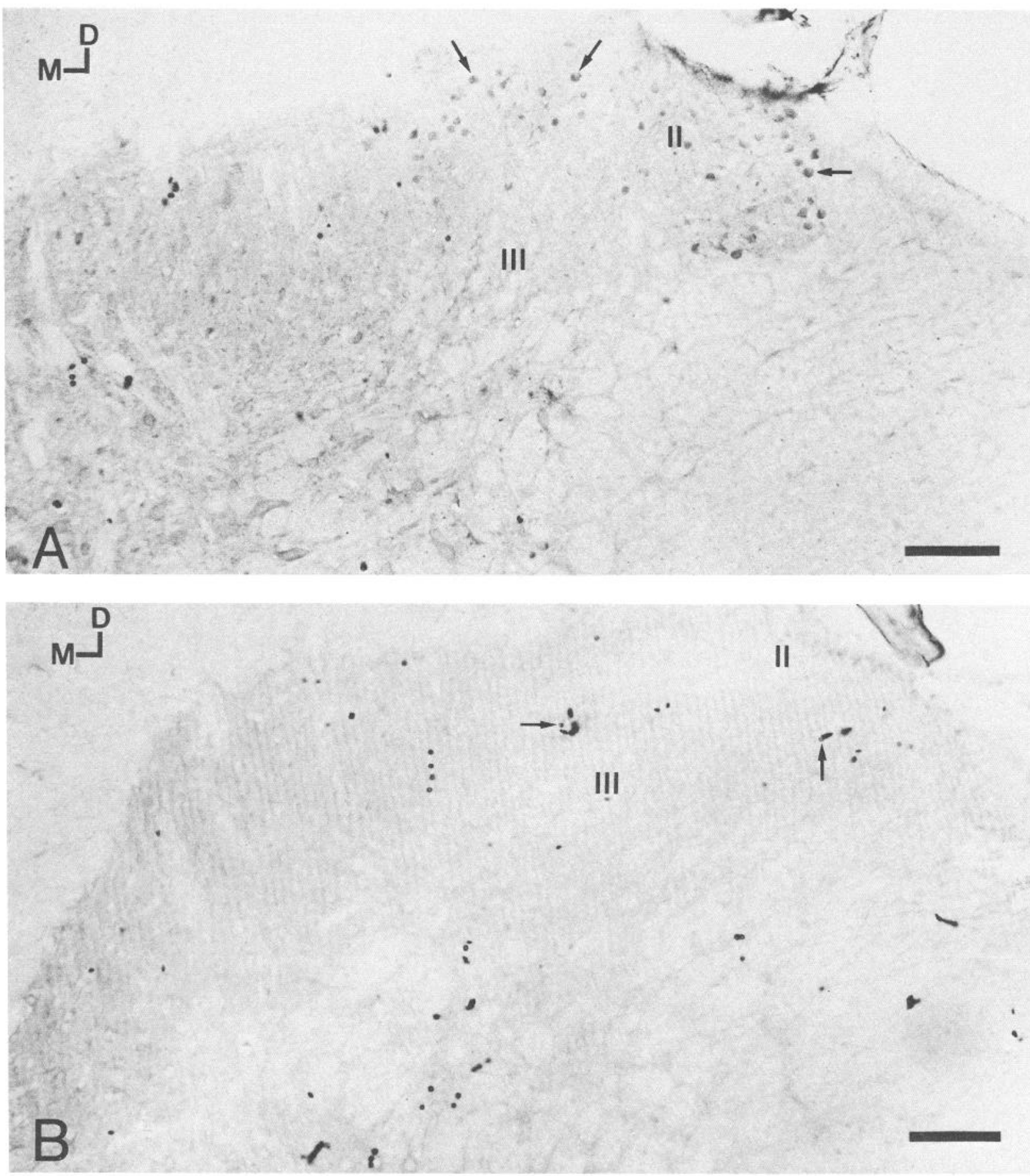

Figure 11. Biotin-avidin staining of the dorsal horn of rat cervical spinal cord by Asp1 in ascitic fluid diluted 1:2000. A, Intense immunoreactivity is evident in neurons (arrows) of layer II but not in other layers of the dorsal horn. II, layer II; III, layer III. B, Inhibition of staining of neurons of the dorsal horn by Asp/KLH $(0.2 \mathrm{mg} \mathrm{KLH} / \mathrm{ml})$. Arrows indicate red blood cells with endogenous peroxidase activity. Tissue was fixed with carbodiimide and glutaraldehyde. $D$, dorsal; $M$, medial. Scale bar, $100 \mu \mathrm{m}$.

be emphasized that Asp1-3 have no appreciable similarities to Glu1 in immunoreactivity for any compounds tested using ELISA. In glutaraldehyde-fixed tissue, it is possible that the antibodies with reactivity for fixative-modified aspartate are detecting a metabolic pool of aspartate in some neurons that will eventually be converted to glutamate and then perhaps to GABA. This would explain why the stellate cells of the cerebellar cortex display both AATase-like and aspartate-like immuno- reactivity when they are considered to be GABAergic neurons. It is of interest that Purkinje cells do not stain with antisera against AATase or with our monoclonal antibodies against fixative-modified aspartate. This raises the possibility that 2 types of GABAergic neurons exist. One type, such as the stellate cells and basket cells, synthesize GABA from glutamate that is obtained from aspartate. The second type, including the Purkinje cells, synthesizes GABA from glutamate that is not obtained 
from aspartate. Several pathways can be used to form glutamate. The recent finding that intense glutaminase-like immunoreactivity and glutamate-like immunoreactivity are colocalized in the same neurons of the spinal trigeminal nuclei of the rat (Magnusson et al., 1986) suggests that at least some of the glutamate in these neurons is formed from glutamine and not aspartate. Further studies using available antibodies and double-labeling techniques for colocalization of excitatory amino acids, GABA, and enzymes that are capable of synthesizing these putative neurotransmitters should further elucidate the synthetic pathways and location of possible neurotransmitter pools of these amino acids.

\section{References}

Anderson, G. W., J. E. Zimmerman, and F. M. Callahan (1967) A reinvestigation of the mixed carbonic anhydride method of peptide synthesis. J. Am. Chem. Soc. 89: 5012-5017.

Balcar, V. J., and G. A. R. Johnson (1972) The structural specificity of the high affinity uptake of L-glutamate and L-aspartate by rat brain. slices. J. Neurochem. 19: 2657-2666.

Beitz, A. J., A. A. Larson, P. Monaghan, R. A. Altschuler, M. M. Mullet, and J. E. Madl (1986a) Immunocytochemical localization of glutamate, glutaminase and aspartate aminotransferase in neurons of the pontine nuclei. Neuroscience 17: 741-753.

Beitz, A. J., M. A. Mullet, J. E. Madl, and A. A. Larson (1986b) Colocalization of putative excitatory amino acid neurotransmitters and their synthesizing enzymes in the brain stem and cerebellum. Anat. Rec. 214 (3):10A.

Benveniste, H., J. Drejer, A. Schousboe, and N. H. Diemer (1984) Evaluation of extracellular concentrations of glutamate and aspartate in rat hippocampus during transient cerebral ischemia monitored by intracerebral microdialysis. J. Neurochem. 43: 1369-1374.

Campistron, G., R. M. Buijs, and M. Geffard (1986) Specific antibodies against aspartate and their immunocytochemical application in the rat brain. Brain Res. 365: 179-184.

Divac, I., F. Fonnum, and J. Storm-Mathisen (1977) High affinity uptake of glutamate in terminals of corticostriatal axons. Nature 266 : 377-378.

Donoghue, J. P., R. J. Wenthold, and R. A. Altschuler (1985) Localization of glutaminase-like and aspartate aminotransferase-like immunoreactivity in neurons of cerebral neocortex. J. Neurosci. 5: 25972608.

Fonnum, F. (1984) Glutamate: A neurotransmitter in mammalian brain. J. Neurochem. 42:1-11.

Friguet, B., A. F. Chaffotte, L. Djavadi-Ohaniance, and M. E. Goldberg (1985) Measurements of the true affinity constant in solution of antigen-antibody complexes by enzyme-linked immunosorbent assay. J. Immunol. Methods 77: 305-319.

Geffard, M., R. M. Buijs, P. Seguela, C. W. Pool, and M. LeMoal (1984) First demonsration of highly specific and sensitive antibodies against dopamine. Brain Res. 294: 161-165.

Geffard, M., J. Dulluc, and A. Rock (1985) Antisera against the indolealkylamines: Tryptophan, 5-hydroxytryptophan, 5-hydroxytryptamine, 5-methoxytryptophan, and 5-methoxytryptamine tested by an enzyme-linked immunosorbent assay method. J. Neurochem. 44: $1221-1228$.

Kimes, A. S., and M. K. Shellenberger. (1983) A method for manual determination of glutamate, glutamine, GABA and aspartate from brain regions. Pharmacol. Biochem. Behav. 18: 943-948.

Lew, A. M. (1984) The effect of epitope density and antibody affinity on the ELISA as analyzed by monoclonal antibodies. J. Immunol. Methods 72: 171.

Madl, J. E., A. A. Larson, and A. J. Beitz (1986) Monoclonal antibody specific for carbodiimide-fixed glutamate: Immunocytochemical localization in the rat CNS. J. Histochem. Cytochem. 34: 317-326.

Magnusson, K. R., A. A. Larson, J. E. Madl, R. A. Altschuler, and A. J. Beitz (1986) Co-localization of fixative-modified glutamate and glutaminase in neurons of the spinal trigeminal nucleus of the rat: An immunohistochemical and immunoradiological analysis. J. Comp. Neurol. 247: 477-490.

Nicklas, W. J., and S. Berl (1973) In vivo studies on the effect of 6-hydroxydopamine on amino acid metabolism in brain. Brain Res. 61: 343-356.

Nieto, A., A. Gaya, M. Jansa, C. Moreno, and J. Vives (1984) Direct measure of affinity distribution by hapten-inhibition enzyme immunoassay. Mol. Immunol. 21: 537-543.

Oi, V. T., and L. A. Herzenberg (1980) Immunoglobulin-producing hybrid cell lines. In Selected Methods in Cellular Immunology, B. B. Mishell and S. S. Shiigi, eds., pp. 358-361, Freeman, San Francisco, CA.

Ottersen, O. P., and J. Storm-Mathisen (1985) Different neuronal localization of aspartate-like and glutamate-like immunoreactivities in the hippocampus of rat, guinea-pig and Senegalese baboon (Papio papio), with a note on the distribution of gamma-aminobutyrate. Neuroscience 16: 589-606.

Palkovits, M., T. Lang, A. Patthy, and I. Elekes (1986) Distribution and stress-induced increase of glutamate and aspartate levels in discrete brain nuclei of rats. Brain Res. 373: 252-257.

Pearce, B. R., and G. R. Dutton (1981) $\mathrm{K}^{+}$-stimulated release of endogenous glutamate, GABA and other amino acids from neuron- and glia-enriched cultures of the rat cerebellum. FEBS Lett. 135: 215.

Peinado, J. M., J. A. Gomez-Capilla, and F. Mora (1984) Cerebral cortex and neurotransmitters: Higher levels of aspartic acid but not GABA in the frontal cortex of the rat. Brain Res. Bull. 12: 625-627.

Rothman, S. (1984) Synaptic release of excitatory amino acid neurotransmitter mediates anoxic neuronal death. J. Neurosci. 4: 18841891.

Sandoval, M. E., and C. W. Cotman (1978) Evaluation of glutamate as a neurotransmitter of cerebellar parallel fibers. Neuroscience 3: 199 206.

Simon, R. P., J. H. Swan, T. Griffiths, and B. S. Meldrum (1984) Blockade of N-methyl-D-aspartate receptors may protect against ischemic damage in the brain. Science 226: 850-852.

Steward, M. W., and A. M. Lew (1985) The importance of antibody affinity in the performance of immunoassays for antibody. J. Immunol. Methods 78: 173-190.

Storm-Mathisen, J., A. K. Leknes, A. T. Bore, J. L. Vaaland, P. Edminson, F. M-S. Haug, and O. P. Ottersen (1983) Glutamate and GABA: First visualization in neurons by immunocytochemistry. Nature 301: 517-520.

Streit, P. (1985) Glutamate and aspartate as transmitter candidates for systems of the cerebral cortex. In Cerebral Cortex, vol. 2, E. G. Jones and A. Peters, eds., pp. 119-139, Plenum, New York.

Toggenburger, G., L. Wiklund, H. Henke, and M. Cuenod (1983) Release of endogenous and accumulated exogenous amino acids from slices of normal and climbing fibre-deprived rat cercbellar slices. J. Neurochem. 41: 1606-1613.

Toomim, C., K. McCarthy, and P. Petrusz (1986) Characterization of antibodies to glutamate and aspartate by immunoblot analysis and immunochemistry. Neurosci. Abstr. 16: 419 (118.4).

Watkins, J. C., and R. H. Evans (1981) Excitatory amino acid transmitters. Annu. Rev. Pharmacol. Toxicol. 21: 165-204.

Wenthold, R. J., and R. A. Altschuler (1983) Immunocytochemistry of aspartate aminotransferase and glutaminase. In Glutamine, Glutamate and GABA in the Central Nervous System, L. Hertz, E. Kbamme, E. G. McGeer, and A. Schousboe, eds., pp. 33-50, Liss, New York.

Wenthold, R. J., K. K. Skaggs, and R. A. Altschuler (1986) Immunocytochemical localization of aspartate aminotransferase and glutaminase immunoreactivities in the cerebellum. Brain Res. 363: 371375.

Wiklund, L., G. Toggenburger, and M. Cuenod (1984) Selective retrograde labelling of the rat olivocerebellar climbing fiber system with D- $\left[{ }^{3} \mathrm{H}\right]$ aspartate. Neuroscience 13: 441-468.

Young, A. B., M. B. Bromberg, and J. B. Penny (1981) Decreased glutamate in subcortical areas deafferented by sensorimotor cortex ablation in the cat. J. Neurosci. 1: 241 . 